\title{
Europe-Africa partnership set to launch clinical trials
}

The European Union (EU) in February kicked off the operational phase of an ambitious clinical research partnership with Africa. But experts warn that the initiative's prioritization could set back the treatment of other, less noteworthy, diseases.

The European and Developing Countries Clinical Trials Partnership (EDCTP) aims to establish centers across Africa for clinical trials of new interventions against HIV, malaria and tuberculosis. The initiative is funded until 2008 by equal contributions of around $€ 200$ million from both the European Commission and EU member states. "This is one of the biggest international research and development efforts against these three diseases," says European Research Commissioner Philippe Busquin.

There is broad support on both continents for the program, which is expected to result in larger, more powerful trials. "The EDCTP is an organization which has massive promise," says Tim Tucker, director of the South African AIDS Vaccine Initiative. The partnership with Europe gives African nations a real opportunity to build local infrastructure and strengthen their contribution to research, Tucker says. Still, it will be a big challenge to empower the African states to go beyond carrying out the instructions of their European partners, he notes.

When funding bodies like the EDCTP focus solely on diseases that cause the greatest mortality, there is a risk that research into other diseases will suffer, warns David Warrell, founding director of the Centre for Tropical Medicine at the University of Oxford."A number of these bodies are now refusing to even consider applications on diseases outside their shortlist," Warrell says.

The EDCTP program could inadvertently have a long-term impact on the development of new treatments for nonprioritized conditions, such as acute respiratory tract infections and diarrheal diseases, or local problems that require therapeutic intervention, Warrell adds. "It ignores the diversity of human suffering," he says.

Piero Olliaro, the EDCTP's new executive director, agrees that more funds must be made available for lesser-known diseases. But focusing on HIV, malaria and tuberculosis will have the greatest impact, Olliaro says. In the long term, he adds, the EDCTP's investment in African facilities can only benefit research into other diseases.

Henry Nicholls, London

\section{UK autism fracas fuels calls for peer review reform}

New rules on research governance in the UK and the European Union could have prevented the publication of The Lancet's 1998 paper suggesting a link between the combined measles, mumps and rubella (MMR) vaccine and autism in children, and averted the ensuing health scare, say health policy experts.

Their comments came as the UK's General Medical Council launched an investigation on Andrew Wakefield, lead researcher on the paper (Lancet 351, 637; 1998). Wakefield had received $\mathfrak{E 5 5 , 0 0 0}$ to lead a study commissioned by the Legal Aid Board on behalf of parents who claimed their children had been damaged by the vaccine. Of the 12 children in the Lancet study, 4 were also involved in the Legal Aid Board study. Both projects were conducted at the Royal Free Hospital in London.

On 20 February, Lancet editor Richard Horton said he would not have published the paper had Wakefield's conflict of interest been disclosed to him. "Such a disclosure would have provided important information to editors and peer reviewers about the context in which this work was taking place," Horton said in a statement.

In early March, 10 of Wakefield's 12 coauthors retracted their interpretation suggesting a possible link between the vaccine and autism. Wakefield did not sign the retraction.

Conflict of interest among researchers is a hot-button issue (Nat. Med. 9, 1340-1341; 2003). As a founding member of the Committee on Publication Ethics (Nature 428, 5; 2004), Horton is campaigning for the creation of an independent UK watchdog to protect the integrity of scientific research. The committee has already issued a code of conduct to editors on how to deal with-among other things - conflicts of interest.

But it's unfair to judge Wakefield by today's standards, says Neil Vickers, a senior lecturer in medical research governance at University College London. "What hasn't found its way into the [news]papers is that the [Legal Aid] study is mentioned in the Lancet paper," he says. "They don't say, 'It's being funded by Legal Aid,' but they do mention it."

The real issue is not Wakefield's conflict of interest, but that The Lancet should never have published such a "scientifically lousy" paper, Vickers says. The study was based on only 12 children, parents were asked to recall the time of onset of symptoms after their

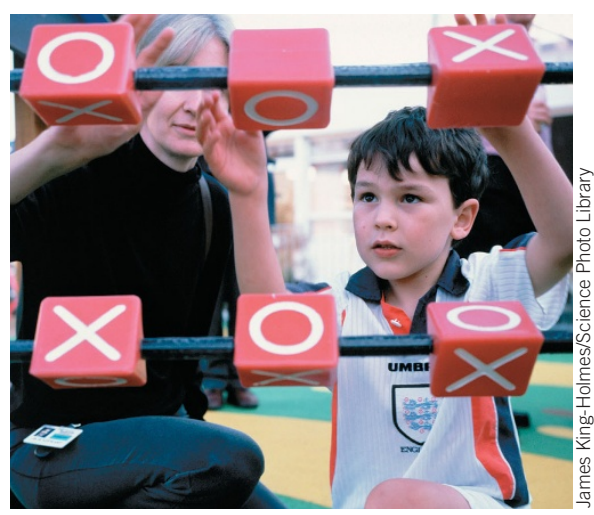

Scientists have retracted their interpretation of results linking autism to the MMR vaccine. children had received the MMR jab, and although the children were recruited consecutively to the study-as good scientific practice demands-many of the parents knew of Wakefield's theories and had asked to be referred to that clinic. The study was therefore almost certainly subject to both recall bias and selection bias, Vickers says.

"It's easy to be an armchair critic with hindsight," Horton told Nature Medicine. At the time, he says, the UK government had been severely criticized for not raising the possibility of bovine spongiform encephalopathy risk, even though that risk was then unproven.

Given the political climate, Horton says, his editorial team faced a difficult decision: whether to omit testimony on a temporal association between vaccination and the onset of symptoms, or include it-with the caveat that no association had yet been proven. "What we couldn't plan for was the fact that Dr. Wakefield would then stand up at a press conference and say, 'Split the vaccine [into the individual components]," he says.

Still, some experts maintain that more rigorous peer review would have resolved the issue. "Were there sufficiently robust peerreview processes in place? Clearly there weren't," says Allyson Pollock, one of the architects of the new research governance framework. Under the new rules, peer review will be legally regulated, Pollock says. "[That] will make it increasingly difficult, though not impossible, to do bad science."

Laura Spinney, London 